\title{
80 ANOS DA OBRA PROJEÇÃO CONTINENTAL DO BRASIL, DE MÁRIO TRAVASSOS
}

\author{
Edu Silvestre de Albuquerque ${ }^{1}$
}

Resumo: O geopolítico Mário Travassos transpôs o conceito mackinderiano de heartland para os altiplanos bolivianos, onde se dava a hegemonia de Buenos Aires, que ainda detinha a vantagem da situação geográfica em relação a extensa Bacia do Prata. Em face disto, Travassos concebe toda uma articulação transversal rodo-ferroviária do "triângulo estratégico boliviano" até os portos atlânticos brasileiros do Centro-Sul e ao complexo ferrohidroviário Madeira-Mamoré, visando a "soldadura do Brasil Platino ao Brasil Amazônico" e a projeção das comunicações brasileiras pelos Andes. Para as demais regiões naturais do país, o geopolítico propunha o desenvolvimento de artérias longitudinais, verdadeiras vias de integração nacional que se somariam à vantagem situacional brasileira em relação a penetração do rio Amazonas para o oeste. Suas ideias influenciaram as políticas de ordenamento territorial do Estado brasileiro, mas atualmente convivem com uma "hegemonia benevolente" sul-americana orquestrada no âmbito do Itamarty.

Palavras-chave: Geopolítica; Redes de Circulação; América do Sul.

\section{YEARS OF THE BOOK CONTINENTAL PROJECTION OF BRAZIL, MARIO TRAVASSOS}

Abstract: The geopolitical Mario Travassos transposed mackinderiano concept of heartland for the Bolivian highlands, where occurred the hegemony of Buenos Aires because of the advantage of location in the La Plata Basin. From there, Travassos conceives a whole road and rail system in transverse lines from the "Bolivian strategic triangle" to the Brazilian Atlantic ports, and vertical lines for rail and waterway complex Madeira-Mamore, aiming to unite the Plata to Brazilian Amazon and project communications through the Andes. In the Amazon, unlike the situational advantage was Brazilian, due to the penetration of the Amazon River to the west. His ideas influenced the policies of territorial planning of the Brazilian state during the twentieth century, but currently living with the regional project in South America of Itamarty.

Key words: Geopolitics; Circulation Networks; South America.

O comércio e a comunicação precedem de muito a política, que segue o seu mesmo caminho e nunca pode se separar profundamente deles. (RATZEL apud MORAES, 1990, p. 182-183).

1. Doutor em Geografia, Docente da Universidade Federal do Rio Grande do Norte (UFRN) (edusilvestre@ufrnet.br). 
No ponto de vista absoluto não há quem desconheça o papel que as comunicações representam na formação e mantença dos Estados. As comunicações podem mesmo definir o grau de aproveitamento das possibilidades de um país como de uma região, exprimir materialmente os objetivos que se prosseguem (TRAVASSOS, 1935, p. 184-185).

\section{INTRODUÇÃO}

O Marechal Mário Travassos (1891-1973) participou da Força Expedicionária Brasileira (FEB) na Segunda Guerra Mundial, foi idealizador e primeiro comandante da Academia Militar das Agulhas Negras (AMAN), membro da comissão que escolheu o local da nova capital federal. Foi presidente da Associação Brasileira de Educação ( $A B E)$, e pertenceu ao quadro de redatores do Jornal do Brasil, além de colaborar nos periódicos Defesa Nacional e O Estado de S. Paulo. Suas ideias inspiraram as políticas de transporte do Estado brasileiro, reforçando as ligações transversais do Brasil com Bolívia e Paraguai e as rodovias longitudinais integradoras do território brasileiro.

Neste ano comemoramos 80 anos de sua obra principal Projeção Continental do Brasil (1935), escrita quando ainda era capitão de Exército, e considerada um marco na geopolítica brasileira ${ }^{2}$. Na obra, apresenta a política interna brasileira indissociável de uma política continental. Aliás, seu ilustre prefaciador Pandiá Cálogeras aponta que a obra fora inicialmente batizada como Aspectos Geográficos Sul-Americanos, e editada em 1931, depois alterada pela detentora dos direitos autorais, a Companhia Editora Nacional, para Projeção Continental do Brasil, seguramente título mais vendável. Foi quando a obra "ganhou várias edições para o castelhano", e "segundo Meira Mattos, foi um dos livros brasileiros mais traduzidos e discutidos pelas repúblicas do arco fronteiriço do Brasil". (MARTINS, 2011, p. 41). ${ }^{3}$

2.. É também do autor "Introdução à Geografia das Comunicações Brasileiras" (1942), pela editora carioca José Olympio. Este livro traz a definição de seu conceito estratégico de linhas de menor resistência, que "se refere às rotas naturais de penetração, isto é, os traços morfológicos do território onde a implantação da infra-estrutura viária é mais fácil e mais barata. Geralmente, os movimentos dos povos nômades seguem as linhas de menor resistência. " (MARTINS, 2011, p.42).

3. Esse novo título cairia ao gosto de críticos dos países vizinhos e da esquerda brasileira por "demonstrar" as pretensões imperialistas do Brasil no subcontinente, quando em realidade o autor apenas vincula o desenvolvimento brasileiro ao sul-americano. Exemplo dessa crítica é a obra de Paulo Schilling, escrita nos 
O pensamento travassiano influenciou diretamente a geração de generais-geopolíticos militares desde Golbery do Couto e Silva até Carlos de Meira Mattos, que basearam suas análises geopolíticos acerca da América do Sul no antagonismo entre Bacia do Prata e Bacia Amazônica tal como definido em Projeção Continental do Brasil ${ }^{4}$.

Para escrevê-la, Travassos encontrou referência no geógrafo alemão Friedrich Ratzel, que destacou em fins do século XIX a importância do fator fisiográfico e antropogeográfico na organização do território, especialmente manifestados no desenvolvimento econômico e na organização das redes de transporte ${ }^{5}$. Também inspira-se no conceito de heartland ("coração da terra"), elaborado no início do século XX pelo geógrafo e diplomata britânico Halford Mackinder para analisar a disputa pelo poder mundial entre os poderes marítimos e as potências terrestres ascendentes. O heartland eurasiático é formado pelas vastas planícies do centro geográfico da Eurásia, ricas em recursos naturais e em situação geográfica favorável para a defesa, e que Travassos translada ao situar um hertland sulamericano na região do altiplano boliviano. É a partir daí que aflora o diálogo com os escritos do geopolítico espanhol Badia Malagrida, onde encontra uma primeira proposta de leitura geográfica da política sul-americana, inclusive na localização do centro geoestratégico sulamericano nas terras bolivianas (MARTINS, 2011) ${ }^{6}$.

O presente ensaio comemorativo tem por objetivo demonstrar a atualidade e validade do pensamento geopolítico de Mário Travassos. Inicialmente, revisitamos a análise geopolítica desenvolvida por Travassos para, no momento seguinte, apontar sua influência nas políticas de organização do território brasileiro. Finalmente, destacamos a atual arquitetura de

anos 70, onde denuncia as pretensões imperialistas brasileiras no subcontinente. Ver SCHILLING, P R. $O$ expansionismo brasileiro. São Paulo: Global, 1981.

4. Martins (2011) faz notar que a "Zona Continental de Soldadura" do autor de Geopolítica do Brasil engloba a Bolívia e partes do Paraguai e do Mato Grosso, desdobrando a ideia do "triângulo estratégico boliviano" de Travassos. Quanto a Meira Mattos, Martins destaca que o autor de Uma Geopolítica Pan-Amazônica reproduz a ideia de Travassos de que o controle brasileiro da foz do Amazonas garante nossa projeção geopolítica por toda a bacia.

5. Acusado de determinista pela Escola Francesa de Geografia, Ratzel em verdade lançara as bases metodológicas para uma Geografia do Homem ou Antropogeografia. A Geografia Política seria o ramo disciplinar responsável por entender a produção das macroestuturas de engenharia que alteram a geografia do planeta, observando a relação Estado - solo.

6. Ver MALAGRIDA, Carlos Badia. El factor geográfico en la política sudamentica. 2a. ed. Madri: Instituto Editorial Reus, 1946 [o original é de 1919]. 
integração física regional e as novas ações do Brasil como principal player geopolítico no subcontinente à luz da análise geopolítica travassiana.

\section{OS ANTAGONISMOS GEOGRÁFICOS SUL-AMERICANOS}

A estrutura analítica da obra Projeção Continental do Brasil parte dos antagonismos geográficos que compartimentam a América do Sul: as relações interregionais são condicionadas pelo Pacífico/Andes ou pelo Atlântico e, numa espécie de subdivisão das áreas de influência deste último oceano, pela Bacia do Prata ou pela Bacia Amazônica, ambas voltadas à vertente atlântica mas com dinâmicas independentes:

Em resumo, na vertente atlântica imensa superfície de contato com os mais possantes centros da civilização mundial, via de penetração natural estendendo-se do oceano às próprias fraldas andinas, mentalidade agrícola, tendências dinâmicas; na vertente pacífica, isolamento marítimo relativo, produção e comunicações que aconchegam características montanhosas, mentalidade mineira, tendências estáticas. (TRAVASSOS, 1935, p. 51). ${ }^{7}$

Observa-se no mapa de Travassos (Figura 1) a importância dos divisores de águas das principais bacias hidrográficas sul-americanas, onde denota-se o destaque atribuído à situação geográfica da Bolívia, mais exatamente ao triângulo Cochabamba-Sucre-Santa Cruz de la Sierra. Esta última aparece como principal ponto de passagem e articulação para as comunicações entre os três principais compartimentos geográficos regionais: o Prata, a Amazônia e os Andes.

Martins (2011, p. 139) destaca ainda o caráter estratégico militar do "triângulo boliviano" em razão da "importância dos nós rodo-ferroviários para os movimentação e suprimento de forças terrestres" em caso de "uma confrontação de caráter continental, tanto entre os

7. Conforme denota Martins (2011, p. 150-151), "O primeiro antagonismo travassiano, ou seja, o impulso dos Estados da vertente do Pacífico para o Atlântico [...] ajuda a compreender a situação boliviana frente ao Brasil, em 1903 e ante o Paraguai, em 1932. Ainda [...] pode-se assinalar que, mais recentemente (na verdade uma questão que se estendeu de 1941 a 1995), o conflito entre o Peru e o Equador pelo vale do rio Cenepa também é explicado por esse princípio, uma vez que este vale dá acesso ao Atlântico por meio do Amazonas. E finalmente, é também a perspectiva de uma projeção chilena para o Atlântico que causaram indisposições entre o Chile e a Argentina em 1978, no episódio do canal de Beagle." 
grandes Estados do continente como contra potências exógenas", constituindo-se na "chave de acesso para qualquer progressão tanto no sentido norte-sul como leste-oeste" ${ }^{8}$

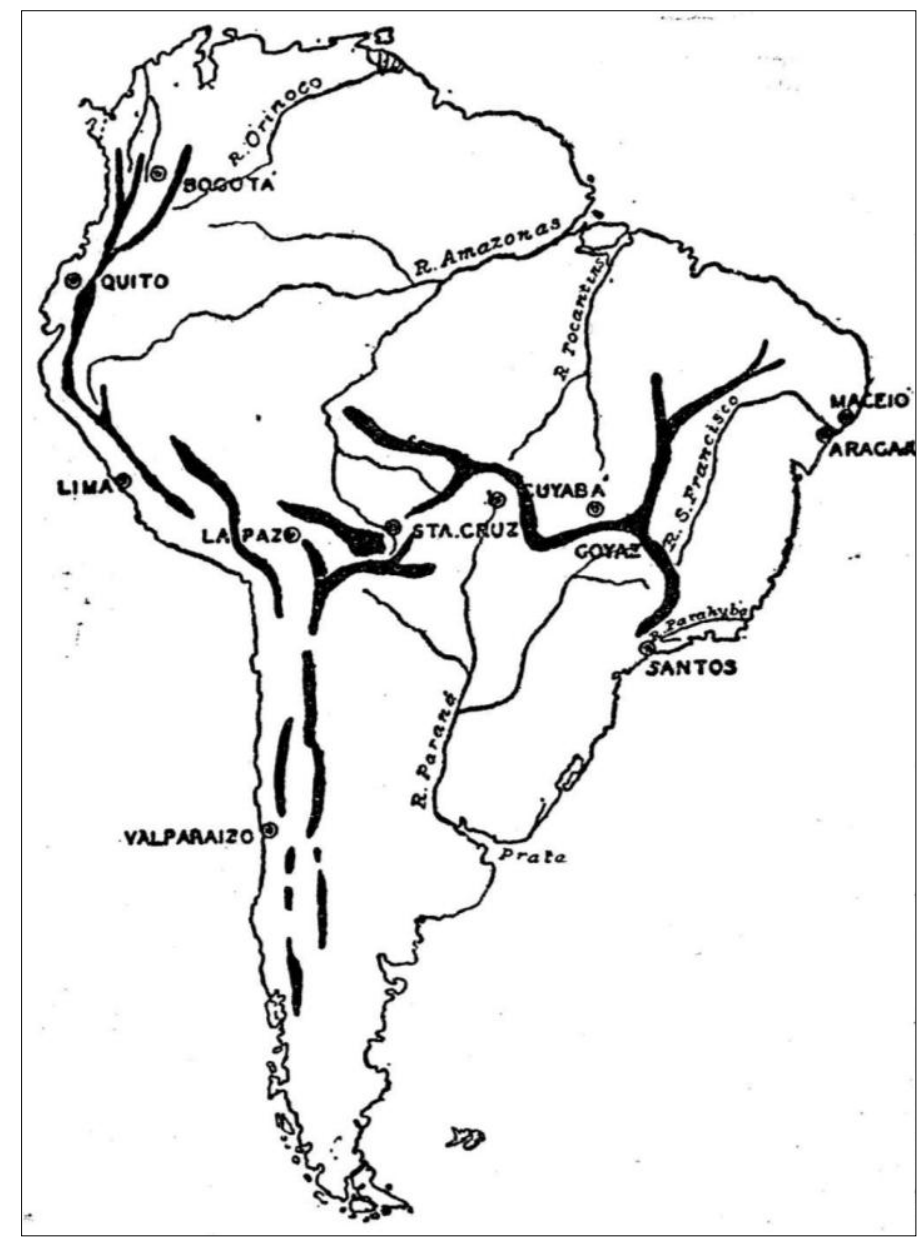

Figura 1: Compartimentos Geográficos da América do Sul. Fonte: TRAVASSOS (1935).

Com efeito, os antagonismos geográficos apontados por Travassos continuam se manifestando no desenho dos atuais agrupamentos regionais no subcontinente. $\mathrm{O}$ advento do Mercosul com o Tratado de Assunção, em 1991, evoluiu a partir dos países do Cone Sul do continente voltados à Bacia do Atlântico. E recentemente, em 6 de junho de 2012, Chile, Colômbia, Peru e México se reuniram para estabelecer a Aliança do Pacífico, uma proposta

8. Acrescente-se ainda a dimensão econômica da região de influência de Santa Cruz, que se fazia notar mesmo antes da extração de hidrocarbonetos e da política de povoamento promovida no governo de Strossner que desenvolve a sojicultura na região atraindo agricultores brasileiros: "Quanto à importância econômica desta vertente [altiplano oriental], Santa Cruz representa-a bem, como o principal centro produtor de toda a imensa zona que vimos tratando. Pradarias e rebanhos sem fim, borracha e trigo são características suficientes para a qualificação econômica desta zona." (TRAVASSOS, 1935, p. 44). 
de bloco comercial mais ligado aos EUA que aos demais países sul-americanos, refletindo a atual situação de suas linhas de comunicação e comércio internacional mais centradas no Pacífico.

\section{OS PLAYERS GEOPOLÍTICOS SUL-AMERICANOS}

As maiores preocupações de Travassos se direcionam para o caráter expansionista da política de comunicações argentina nos altiplanos e planícies da Bolívia, refletindo "a intenção do presidente Hipólito Yrigoyen, e depois do ministro Matias Sorondo (ministro do interior do general golpista Félix Uriburu), de restaurar o vice-reinado do Rio da Prata" (BANDEIRA, 1998, VIEIRA, 2008 apud MARTINS, 2011, p. 66).

No começo do século XX, a Argentina possuía um plano de comunicações terrestres de caráter continental, que tinha no porto de Buenos Aires o ponto de fuga de um complexo ferroviário que articulava as principais cidades do Paraguai e da Bolívia, com ramais importantes no Chile e no Uruguai (MARTINS, 2011, p. 46).

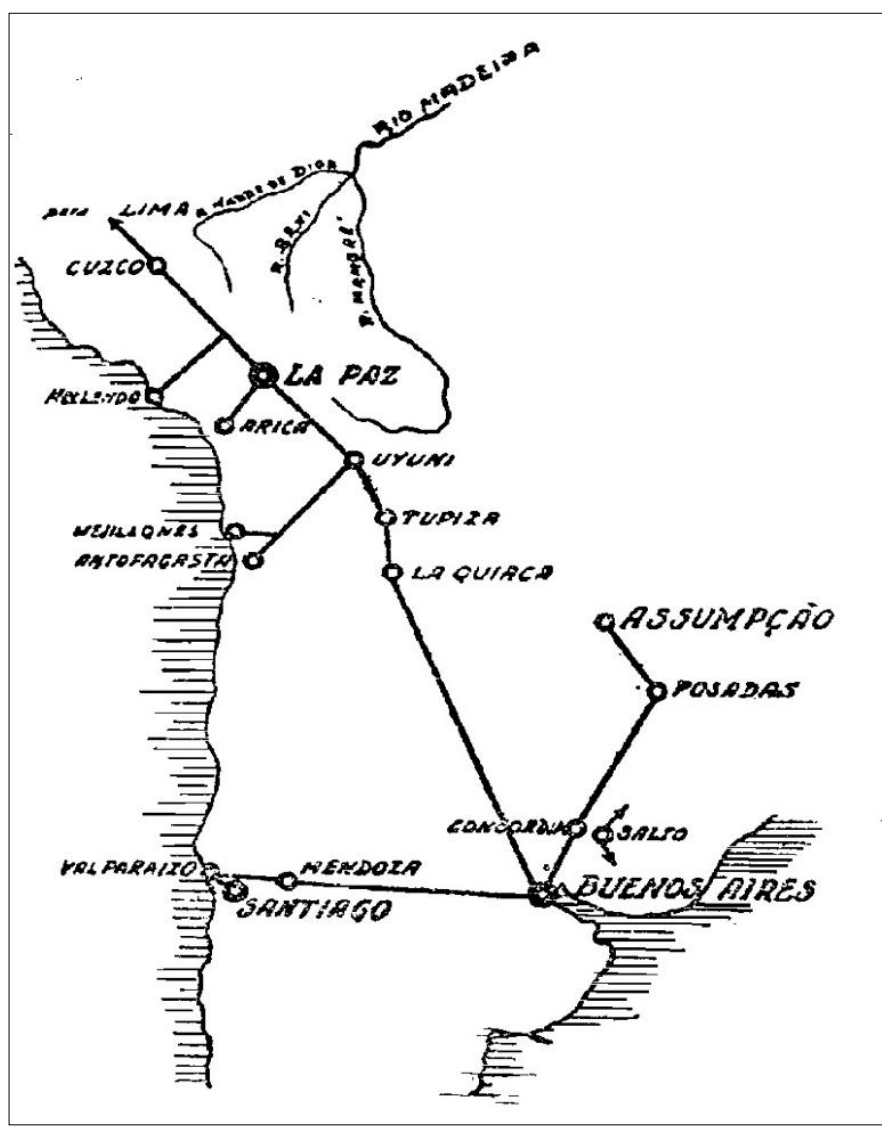

Figura 2: Projeção Geopolítica da Rede Ferroviária Argentina. Fonte: TRAVASSOS (1935). 
Com efeito, ao estender as comunicações da Bacia do Prata até o Pacífico, as redes férreas argentinas representavam uma engenharia espetacular capaz de minimizar os efeitos dos antagonismos geográficos sul-americanos representados pelos Andes e pelas distâncias interoceânicas (Figura 2).

A maior preocupação de Travassos era o ramal ferroviário argentino que se estendia até La Paz, afinal ali se tratava do aumento da influência de Buenos Aires sobre o heartland sulamericano, com possibilidade de hegemonização econômica de todo o subcontinente, incluindo ai o norte do sistema Pacífico-Andes e as cabeças dos vales do Rio Madeira: [a Bolívia] vinculada ao território do Pacífico pela contextura andina da parte ocidental de seu território é, em seguida, em sua parte central e oriental, violentamente dissociada pela repulsão das bacias platina e amazônica. (TRAVASSOS, 1935, p. 80).

Portanto, trazer a região de Santa Cruz de la Sierra, justo onde se manifestam as "forças dissociadoras da Bolívia mediterrânea", à órbita brasileira fazia-se fundamental, o que Travassos esperava alcançar por meio do rodoviarismo e do prolongamento dos trilhos da Noroeste que já ligavam Corumbá a Santos desde a década de $1910^{9}$ - e que poderia conectar-se então aos trilhos da Madeira-Mamoré, já penetrando a Amazônia. Com efeito, em 1938 o governo Vargas estabelece a ligação rodoviária entre Corumbá e Santa Cruz de la Sierra, conforme as recomendações de Mário Travassos, mas as ligações ferroviárias pretendidas nunca aconteceram, bem como as indústrias do Sudeste brasileiro ainda aguardam a interligação dos portos brasileiros aos portos chilenos e peruanos via altiplano boliviano. $^{10}$

Essa política de articulação rodoviária transversal seria aplicada também ao Paraguai. 0 Brasil inaugurava em 1969 a BR-277, cruzando o estado do Paraná desde Foz do Iguaçú, na

9. O último trecho da ferrovia entre Bauru e Corumbá foi concluído em setembro de 1914 (GHIRARDELLO, 2002).

10. Na opinião de Travasos, a extensão das linhas de comunicação bolivianas até o porto de Santos oportunizaria àquele país maior equilíbrio geopolítico para vencer as forças dissociadoras que as puxam ao porto de Buenos Aires: "As atrações do sul encontram, por sua vez, sérios obstáculos. Por Cochabamba há a distância para o escoadouro de Buenos Aires: Santa Cruz-Cochabamba-Buenos Aires 3.285 km" (TRAVASSOS, 1935, p.85). Enquanto que a construção da linha Santos-Santa Cruz-Puerto Suarez "levaria ao Atlântico, $1.600 \mathrm{~km}$, de costa acima da foz do Prata (Santos), através de $2.576 \mathrm{~km}$, ou seja cerca de $700 \mathrm{~km}$, de menos que por Buenos Aires". (TRAVASSOS, 1935, p. 86). 
fronteira com o Paraguai (onde interliga-se à Ruta 7 ou Rodovia Transparaguaia, que segue no mesmo sentido até Assunção e depois inflete-se para a Bolívia), até o porto de Paranaguá, oferecendo ali instalações para o comércio exterior paraguaio. ${ }^{11}$

Os vastos recursos naturais do heartland sul-americano estavam agora à disposição do Brasil, especialmente com a construção da Usina Hidrelétrica Binacional de Itaipu (iniciada nos anos 70), com o Paraguai, e do Gasoduto Brasil - Bolívia (anos 90), fazendo notar a antevisão estratégica manifestada por Mário Travassos. ${ }^{12}$

\section{AS ZONAS DE INSTABILIDADE POLÍTICA}

Para Travassos (1935, p. 61) a instabilidade geográfica sul-americana deriva da oscilação de alguns países entre determinadas características físicas que os circundam e da cobiça internacional, isto é, representa o produto da dissociação entre a geografia e as unidades políticas sul-americanas. Com o recurso desse método geopolítico, Travassos situa a Bolívia como principal foco de instabilidade política na América do Sul, onde as sucessivas crises políticas e guerras na história desse país são manifestações fenomênicas dos antagonismos geográficos entre suas partes andina, platina e amazônica que operam poderosas forças centrífugas. ${ }^{13}$ Afinal, a Bolívia era então o peão geopolítico mais importante da disputa entre

11. Como diz Martins (2011,), a influência de Travassos se faz notar desde 1934, com o plano geral de viação, passando pela opção rodoviarista do Plano Salte (1944), no governo Dutra. Mas foi com o "regime iniciado em 1964 [...] que as ideias de Travassos foram mais aplicadas. O apoio ao golpe de Estado, que levou ao poder o general Banzer na Bolívia, a construção da usina de Itaipu, a construção de grandes obras viárias como a transamazônica, a construção do porto de Rio Grande e a concessão de ancoradouros francos para Paraguai e Bolívia nos portos brasileiros de Santos e Paranaguá são exemplos de como o Brasil usa sua infra-estrutura viária e energética para atender os objetivos geopolíticos formulados desde a década de 1930." (MARTINS, 2011, p. 76).

12. Da mesma forma, até hoje, as políticas de desenvolvimento regional passaram a enfatizar as chamadas regiões periféricas. O Centro-Oeste e Norte são, inclusive, as regiões de maior crescimento econômico nas últimas décadas. Reflexo disto, a participação destas duas macroregiões no total da população brasileira passou de 7,7\%, em 1962, para 11,3\%, em 1983 (IBGE); e em 2004, ambas já reuniam 14,9\% da população brasileira.

13. No caso boliviano o interesse externo se traduziu na amputação de territórios bolivianos na Guerra do Pacífico, na Questão do Acre e na Guerra do Chaco, respectivamente, para Chile, Brasil e Paraguai. Seu desfecho mais recente foi o mal estar diplomático no Itamaraty diante da desapropriação em 2006 dos ativos da Petrobras na Bolívia, seguido, no ano seguinte, do aumento do preço do gás exportado ao Brasil pelo gasoduto boliviano-brasileiro (Gasbol). 
Argentina e Brasil pela hegemonia na Bacia do Prata e centro do continente, porta de entrada para a vertentes ocidental dos Andes e da Amazônia.

O agrupamento Colômbia/Panamá forma outra área de instabilidade política em razão da divisão entre fachada atlântica e pacífica, quase totalmente dissociado do restante da massa continental sul-americana, tal como a Venezuela, Equador e Guianas. Isso representa que o noroeste da América do Sul - pela dispersão orográfica de suas bacias - é a zona mais frágil à penetração de "interesses extra-continentais":

O Canal do Panamá - verdadeiro carrefour internacional - e o Mar das Antilhas - incubadora da influência yankee - exprimem bem o caráter das pressões que se exercem nessa extremidade do continente sul-americano. As linhas naturais de penetração, que os vales do Madalena e do Orinoco representam, dizem o resto. (TRAVASSOS, 1935, p. 71) ${ }^{14}$.

Essa penetração estadunidense no noroeste sul-americano se operava no avanço dos interesses petrolíferos na Bacia do Madalena e na produção de borracha na Amazônia brasileira (a Fordlândia), e que ambicionava alcançar também o centro geográfico do continente:

Embora não seja fácil prognosticar, tudo faz crer que os maiores progressos da infiltração dos interesses norte-americanos em nosso continente se farão pelas vias andinas e ao longo da costa do Pacífico. Corroboram nosso prognóstico, além das facilidades fisiográficas, o fracionamento político do território. (TRAVASSOS, 1935, p. 100).

Nesse contexto, as legislações nacionalistas do setor petrolífero de Equador e Bolívia seriam medidas reativas dos sul-americanos, como registra Travassos. Analogamente, os recentes golpes brancos contra Zelaya em Honduras (2009), o Plano Colômbia (2000 até o presente) e a pressão diplomática contra o bolivarianismo na Venezuela, além da já citada Aliança do Pacífico, podem ser lidos como novos capítulos dessa "influência yankee" na zona de transição entre o Caribe e o noroeste sul-americano.

14. Para Travassos, as ligações marítimas fomentadas pelos EUA agem em detrimento das forças integradoras sul-americanas, e a própria construção do Canal do Panamá indica esse potencial fragmentador do interesse estadunidense na região, amputando territorialmente a Colômbia e dividindo em duas partes o próprio Panamá. Ainda para o autor, o isolamento mexicano só faria ampliar-se em caso da concretização de um segundo canal na Nicarágua [justamente uma das áreas cogitadas recentemente pela China que pretende ter seu próprio canal na região]. 
Por fim, o terceiro caso de instabilidade política seria o Uruguai, cujo relevo o enquadra no território brasileiro e hidrografia ao território argentino. Por essa razão, emerge como Estado-tampão para equacionar a rivalidade argentino-brasileira decorrente dessa geografia disjuntiva que servia à uma política externa pendular. Aliás, o governo imperial brasileiro já havia formado vasta rede ferroviária unindo a Campanha Gaúcha ao porto de Rio Grande, bem como diversas modernizações deste porto foram empreendidas para retirar a zona pecuarista gaúcha da influência do porto de Montevidéu ${ }^{15}$.

\section{A INTEGRAÇÃO DO CENTRO-OESTE BRASILEIRO}

O Brasil de Mário Travassos é a síntese do mundo sul-atlântico, cumprindo o papel de hegemon benevolente ou estabilizador entre as forças dissociadoras das bacias platina e amazônica. ${ }^{16}$ Pelo Rio Amazonas a penetração brasileira é mais ampla, "pois o vale amazônico é o grande coletor do formidável anfiteatro que se arqueia de Caracas a La Paz" (TRAVASSOS, 1935, p. 114); enquanto que no Brasil Platino, para contrabalançar a força centrípeta do Prata, exige-se meios artificiais para a ligação com o oceano, onde "o sul de Mato Grosso, prolongando os territórios paulistas e paranaense, representa a sua força de penetração" (TRAVASSOS, 1935, p. 114).

Para anular a influência argentina e também a penetração norte-americana em franco progresso na direção do coração sul-americano, tornava-se urgente desenvolver e integrar o Centro-Oeste (Mato Grosso), região que se projeta pelo "centro geográfico do continente (planalto boliviano), seja por meios artificiais (porto de Santos - rede paulista - Noroeste), seja por vias mais que espontâneas, como os rios da bacia amazônica." (TRAVASSOS, 1935, p. 115).

15. Ainda, a construção de ferrovias numa região historicamente dominada pelo latifúndio pecuarista ilustra perfeitamente o caráter estratégico desta malha para a defesa nacional, garantindo o rápido e massivo emprego de tropas militares e provisões em caso de novo conflito no Prata.

16. Em Travassos a projeção continental do Brasil parece mais associada à ideia contemporânea de hegemonia benevolente que ao imperialismo. Por sua vez, o papel do hegemon benevolente pode ser melhor compreendido com a Teoria da Estabilidade Hegemônica (TEH), de Robert Gilpin (2004), que afirma a necessidade da hegemonia de determinados Estados para assegurar o equilíbrio do sistema internacional, já que é o "estabilizador" quem produz normas e bens públicos internacionais e oferta segurança para o comércio internacional. 
Travassos aposta nas "ligações artificiais" representadas pelas estradas e ferrovias para inibir as tendências centrífugas da Bacia do Prata especialmente em relação ao Mato Grosso. Mas para a Vertente Oriental dos Planaltos e o Nordeste Sub-Equatorial - duas regiões integralmente brasileiras -, Travassos vai propor uma organização viária longitudinal, obedecendo a orientação das calhas de suas bacias hidrográficas. ${ }^{17}$

Com efeito, o desenho das rodovias federais na área de influência da fachada atlântica viria a seguir exatamente esse sentido longitudinal apontado por Travassos. O pano de fundo é o Governo JK, que na década de 1950 estimula a atração de montadoras automobilísticas estrangeiras e inicia a construção da nova capital no interior do país, impulsionando o desenvolvimento rodoviário brasileiro. Assim, a BR-116 ligaria o Rio Grande do Sul ao Rio Grande do Norte, primeiro com a conclusão do segmento São Paulo-Porto Alegre (segunda metade dos anos 50), depois com o segmento Rio-Bahia (concluído em 1963). A BR-153 ou Belém-Brasília (que em verdade prolonga-se até o Rio Grande do Sul) foi inaugurada em 1959. ${ }^{18} \mathrm{Na}$ atual década, estamos em plena execução da Ferrovia Norte-Sul, que segue em paralelo à Bacia do Araguaia-Tocantins.

17. É brilhante sua síntese da formação territorial brasileira: "De fato, a história o confirma sobejamente. A via marítima assegurou muitas vezes nossa unidade política, e as vias terrestres, com o vai-vem de paulistas aos confins do Piaui, conduziram os lanços da expansão fomentadora da unidade social e econômica brasileira." (TRAVASSOS, 1935, p. 116).

18. Ministério dos Transportes. Disponível em http://www.transportes.gov.br/conteudo/60924. Acesso em 28 maio de 2014. 


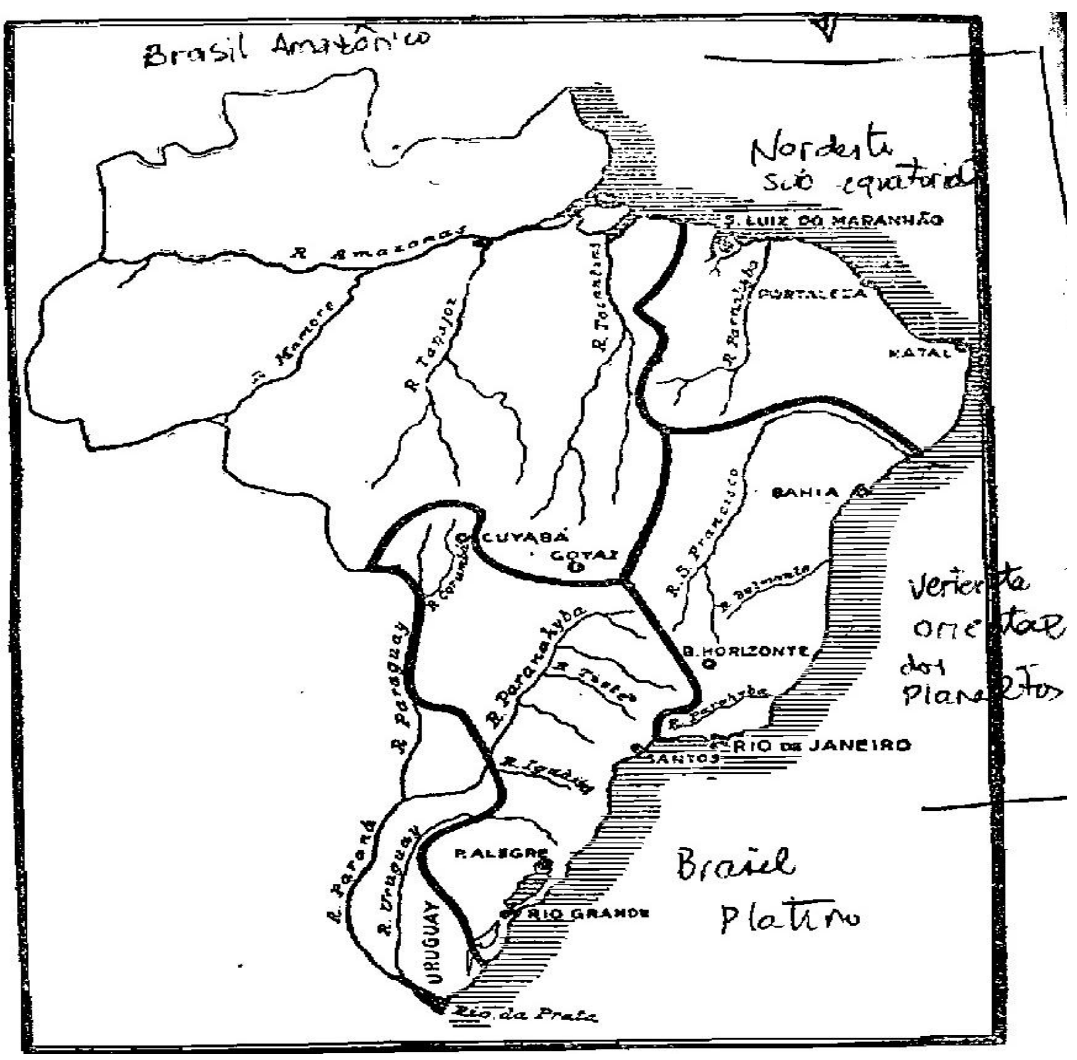

Figura 3: Divisão Regional do Brasil Fonte: TRAVASSOS (1935).

Contudo, quanto mais a oeste, mais essas novas linhas de comunicação entre os Brasis platino e amazônico precisam articular-se ao centro geográfico sul-americano (Figura 3). Nos termos do autor, trata-se de fazer avançar o "Brasil Longitudinal" de modo a minimizar os efeitos de atração do vetor Pacífico-Andes sobre nossos vizinhos.

\section{A VERTEBRAÇÃO DO ESPAÇO SUL-AMERICANO}

A análise geopolítica empreendida por Mário Travassos pode ser utilizada para avaliar o atual planejamento da infraestrutura rodoviária sul-americana no âmbito da IIRSA (Iniciativa para a Intregação da Infraestrutura Regional Sul-Americana). No Eixo Brasil-BolíviaPeru/Chile (também chamado de Eixo Interoceânico Central) observa-se claramente a centralidade da cidade boliviana de Santa Cruz de la Sierra para colocar em contato a vertente atlântica e pacífica sul-americana, justamente a melhor opção para conectar a área industrial do triângulo São Paulo-Rio-Belo Horizonte ao Pacífico, e ainda de modo a evitar o controle da rota pela Argentina (Figuras 4 e 5). 
Nesse eixo, o trecho entre Belo Horizonte-Corumbá-Porto Suárez-Santa Cruz de la SierraCochabamba-La Paz "já existe em quase sua totalidade", mas ainda é preciso resolver a questão da "inexistência de alguns trechos nas fronteiras entre Bolívia e Brasil, e entre Bolívia e Paraguai, [que] dificultam uma interconexão interoceânica de alta capacidade", já anunciada pela IIRSA (ANTUNES, 2007, p. 100). O autor menciona que "Na Bolívia não existe conexão entre os sistemas ferroviários do oriente e ocidente, sendo que a Cordilheira não é cruzada por esta forma de transporte", mas traz a alviçareira notícia de um projeto ferroviário a ser executado com recursos chineses para interligar a região ferrífera do oriente boliviano a um mega-porto no Peru, o que seria fundamental para a vertebração ferroviária do Eixo da Interoceânica Central.

No Eixo de Capricórnio da IIRSA, mais exatamente no Grupo 3, também se percebe a orientação travassiana no sentido das ligações terrestres leste-oeste, com grande destaque para a expansão do modal ferroviário, agora prolongando os trilhos paranaenses até a fronteira com o Paraguai (Figura 6). A reforma e construção de novas rodovias e ferrovias do Paraguai e norte da Argentina até os portos do Pacífico (norte do Chile) são contemplados nos outros Grupos do Eixo de Capricórnio, efetivando mais um importante corredor bioceânico, este mais ramificado e cortando áreas economicamente mais dinâmicas que o corredor bi-oceânico que vai do Acre ao norte do Peru.

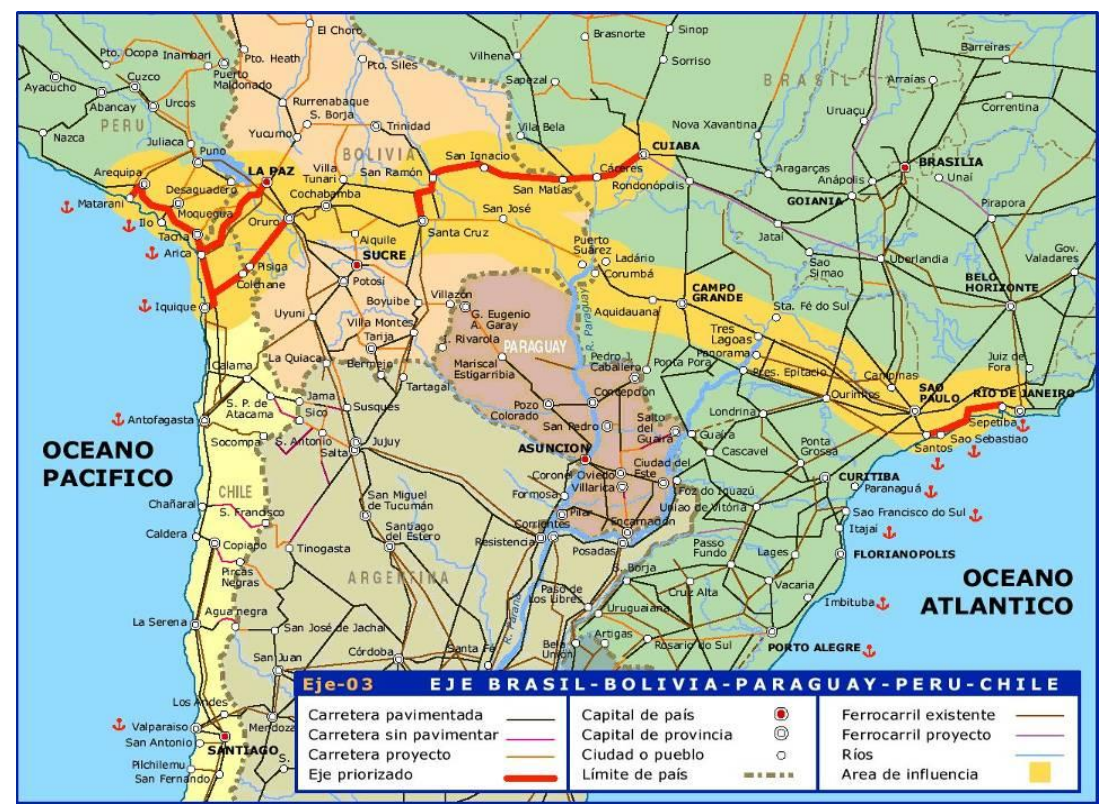

Figura 4: Eixo Brasil-Bolívia-Peru/Chile / IIRSA Fonte: IIRSA (2013). 


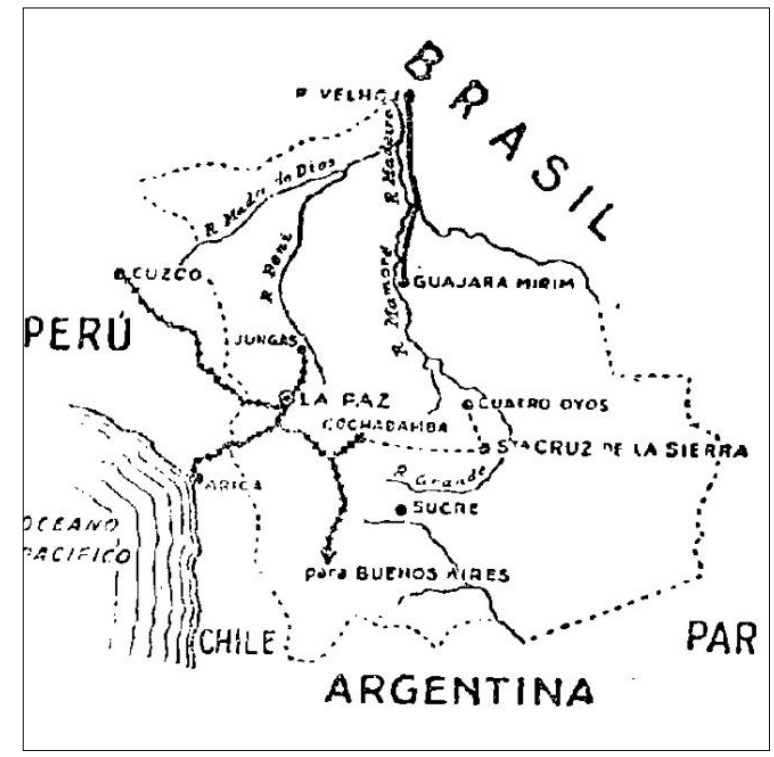

Figura 5:Triângulo Estratégico Boliviano de Travassos Fonte: TRAVASSOS (1935).

No Eixo Andino da IIRSA, observa-se claramente que a organização das rotas rodoviárias no Pacífico é orientada em paralelo à cadeia montanhosa dos Andes (Figura 7), e que as ligações longitudinais são efetivamente a melhor maneira à disposição do Brasil para projetar sua influência nos países andinos. No caso do Eixo Andino observa-se que seguem a orientação da Rodovia Panamericana, principal tronco de comunicação entre as Américas.

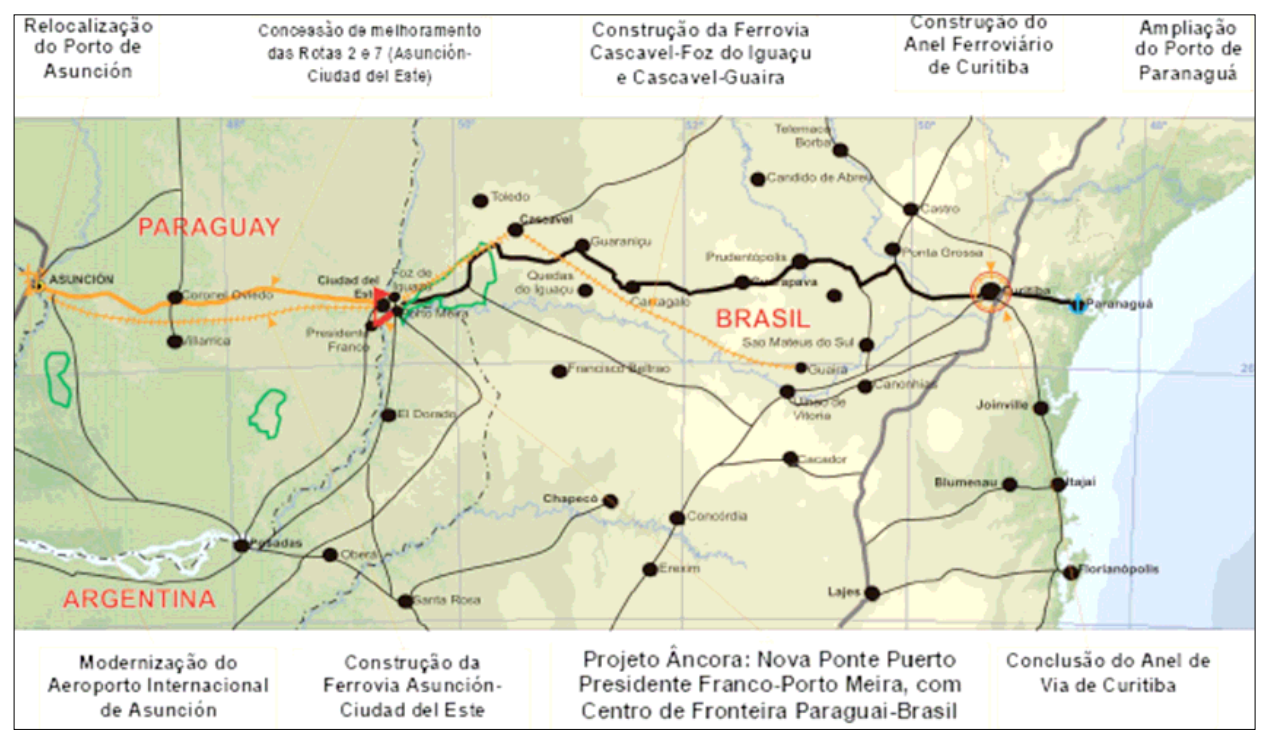

Figura 6: Grupo 3 do Eixo de Capricórnio / IIRSA Fonte: ANTUNES (2007). 


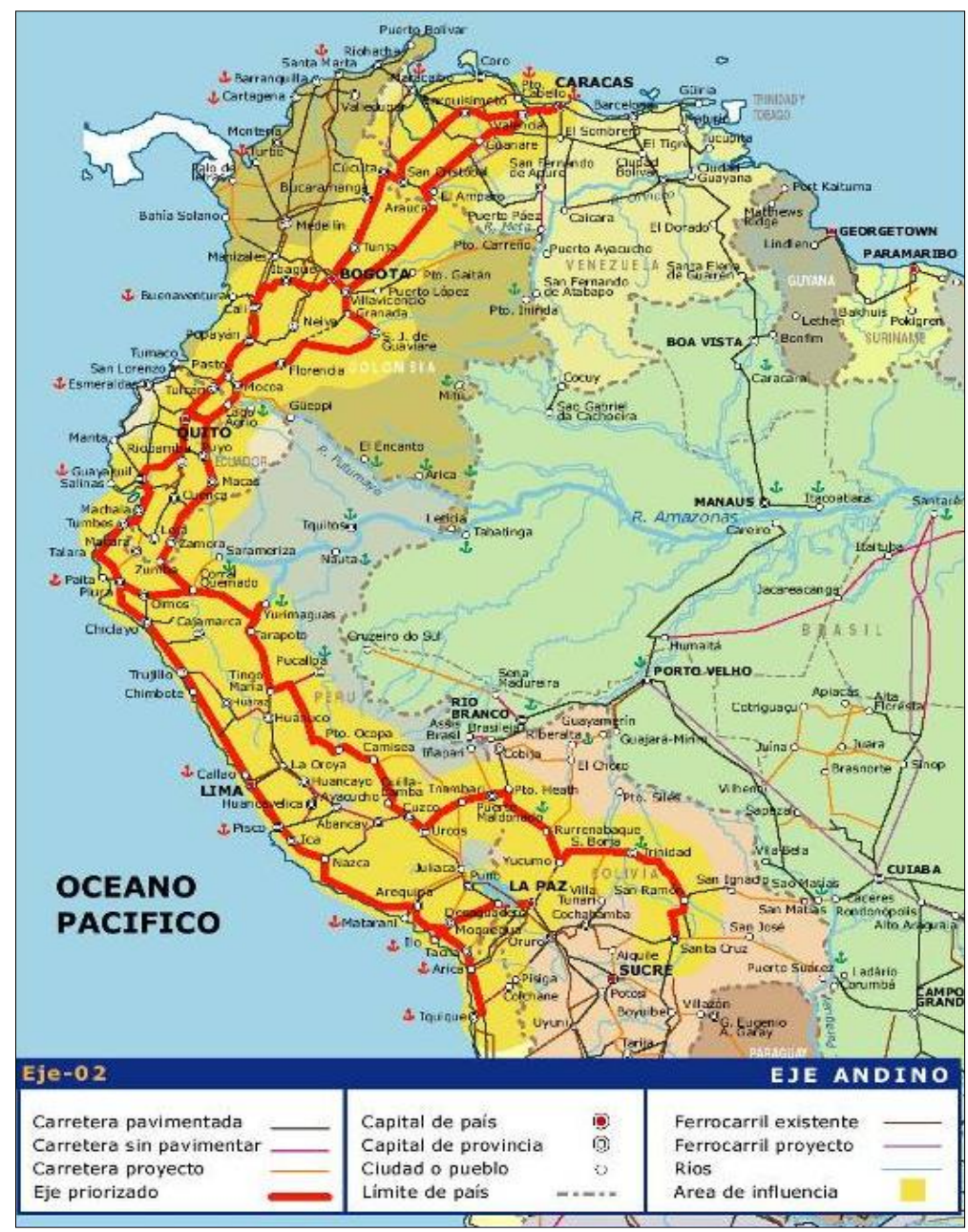

Figura 7: Eixo Andino / IIRSA

Fonte: IIRSA (2013).

Todos os Eixos da IIRSA que conectam as vertentes do Atlântico e do Pacífico passam pelos mais importantes pasos e nudos andinos, incluindo ai já executadas Rodovia Interoceânica (Brasil-Peru) e Rodovia do Mercosul (Brasil-Argentina-Chile). Observa-se que Travassos destacava a importância dessas passagens andinas para conectar o espaço amazônico brasileiro aos países andinos, projetando toda uma influência brasileira pelo anfiteatro que vai de Caracas até La Paz (Figura 8), e assim anulando a influência estadunidense via Rodovia Panamericana. 
A vertebração do território sul-americano pelo Rio Amazonas também se faz no âmbito da IIRSA através do Eixo do Amazonas, com conexões rodoviárias pelas passagens andinas para alcançar o Pacífico (Figura 8) ${ }^{19}$.

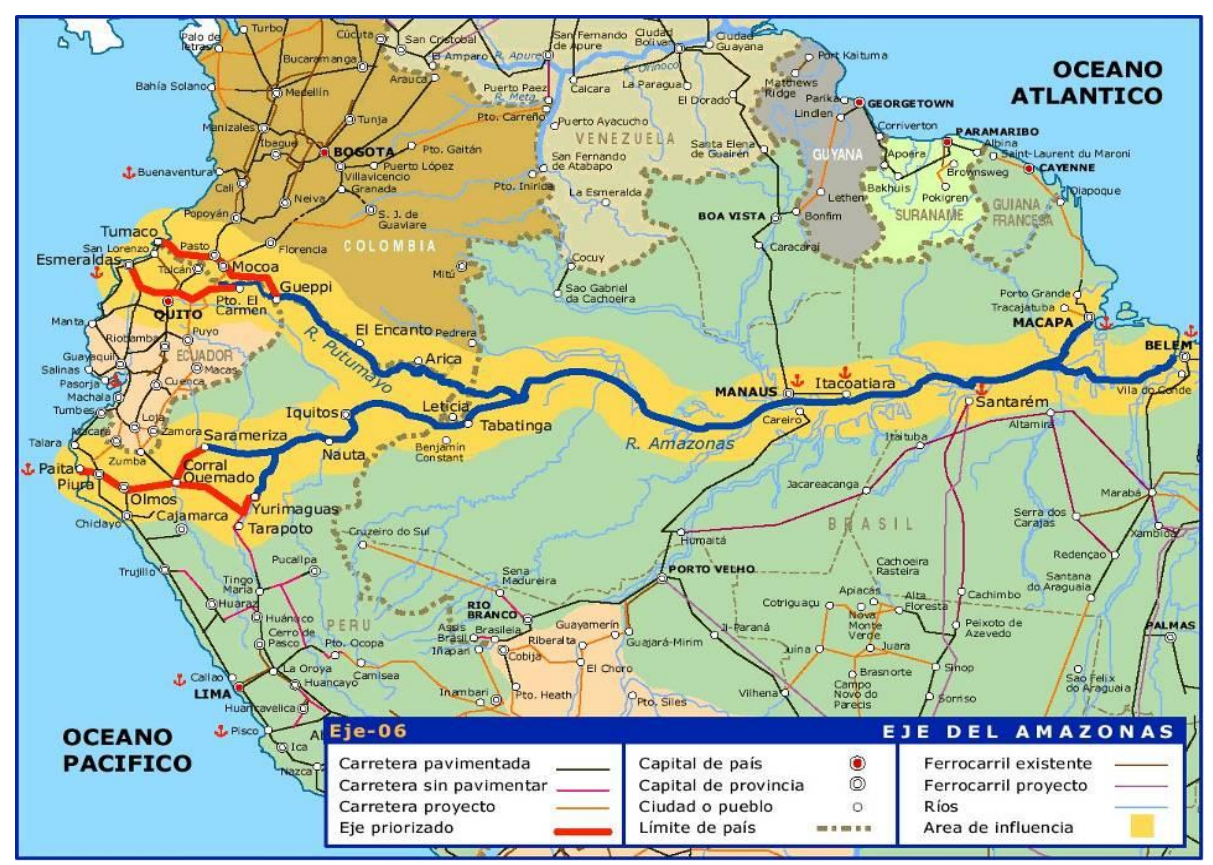

Figura 8: Eixo do Amazonas / IIRSA Fonte: IIRSA (2013).

19. Conforme Travassos (1935, p. 57): "Quando as possibilidades carreadoras da Amazônia se verificarem a pleno rendimento e conjugadamente com as abertas andinas, excluíndo apenas o Paso de Uspalata, as bocas do Amazonas despejarão no Atlântico grande parte da riqueza do centro e da vertente ocidental do continente." 


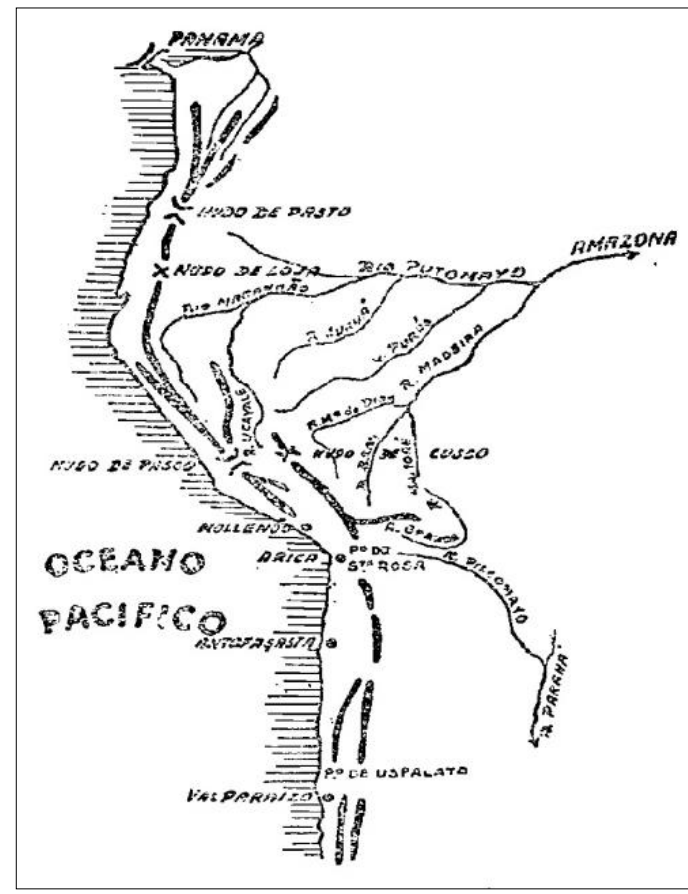

Figura 9: Corredor Amazonas - Andes Fonte: TRAVASSOS (1935).

No Eixo Brasil-Venezuela-Guianas a orientação longitudinal da BR-174, seguindo os divisores de águas da Bacia do Rio Negro e da Bacia do Orinoco, também segue a metodologia geopolítica pensada por Travassos, ali projetando os interesses brasileiros pelo Caribe e enlaçando as Guianas (Figura 10). Esse eixo representa a maior garantia de que a adesão da Venezuela ao Mercosul é agora condicionada também pela geografia e não apenas por eventuais alinhamentos ideológicos entre Brasilía e Caracas.

A BR 174 poderá contrabalançar a dispersão geográfica venezuelana que decorre da orientação de seus vales andinos no sentido do desague das Bacias do Orinoco. Mas é preciso um projeto de colonização e de desenvolvimento industrial do entorno dessa rodovia para que possa efetivamente servir de eixo vertebrador sul-americano e afastar a "influência yankee" como dizia Travassos (1935).

Entretanto, as articulações das comunicações do território brasileiro com a Colômbia são ainda inexistentes, implicando em sérios riscos geopolíticos ao continente, haja visto que ali ocorre uma forte penetração estadunidense sob a alegação do "combate ao narcotráfico". 


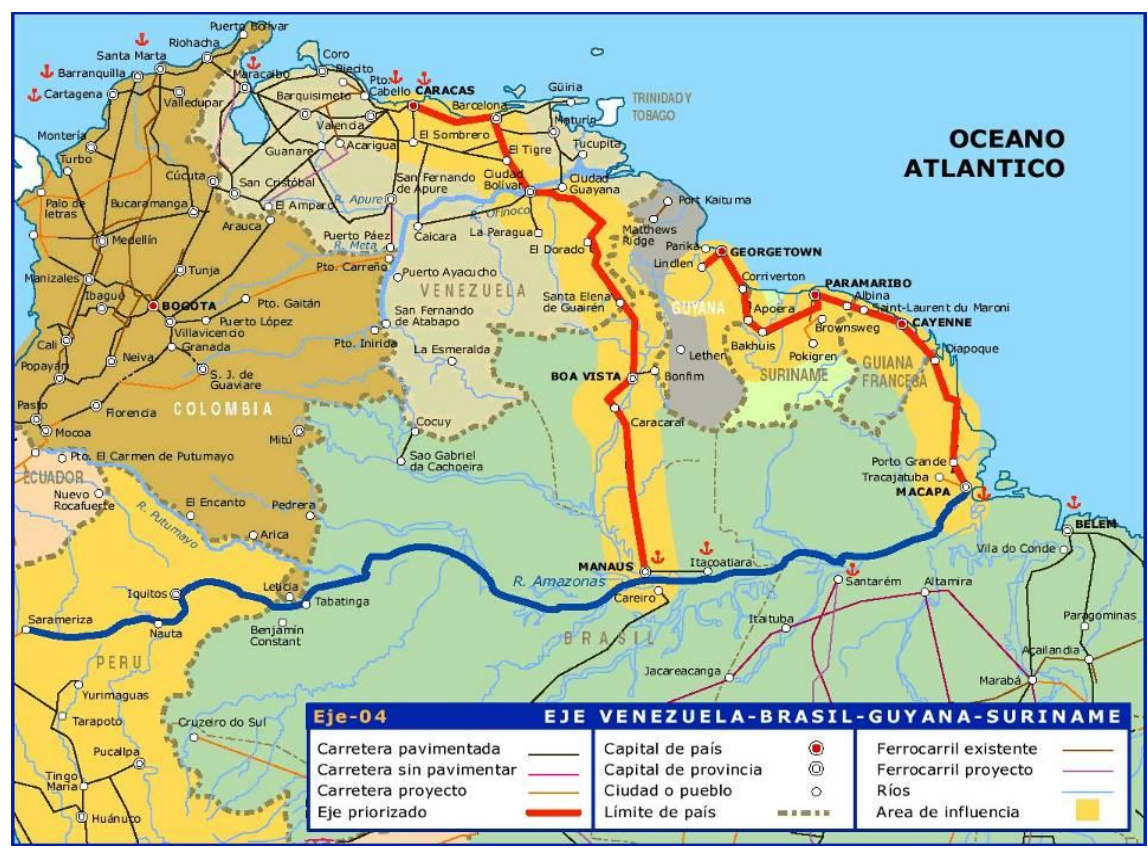

Figura 10: Eixo Brasil-Venezuela-Guianas / IIRSA Fonte: IIRSA (2013).

\section{CONSIDERAÇÕES FINAIS}

Como bem demonstra Santiago (2013, p. 197), a essência do pensamento ratzeliano reside na "relação entre a rede geográfica (circulação/comunicação) e o valor das vantagens da situação territorial", e é este o caminho metodológico trilhado brilhantemente por Mário Travassos em sua análise da projeção continental do Brasil.

Travassos faz continuar a tradicional política externa brasileira dos tempos imperiais, que interveio na luta entre os caudilhos castelhanos para evitar a formação de um Estado que restituisse a vastidão territorial do Vice-Reinado do Rio da Prata (BANDEIRA, 1888; MARTINS, 2011). Desde o Império até a primeira década do séc. XX, as ligações com o Mato Grosso passavam fundamentalmente pelo rio Paraná e pela foz do Prata, o que dava a dimensão da vantagem da situação geográfica de Buenos Aires. Mas ao longo do século XX, a Bolívia e o Paraguai foram soldados à costa brasileira por uma série de modais terrestres de orientação transversal, construídos antes e depois de Travassos.

O antagonismo geográfico sul-americano entre Atlântico e Pacífico continua relevante até nossos dias, como demonstra a configuração do bloco da Aliança do Pacífico. Mas nada para o Itamaraty preocupar-se se Travassos estiver certo quanto às vantagens da vertente 
atlântica sul-americana, afinal os Andes tendem a encurtar a área de influência do Pacífico e prolongar a do Atlântico.

$\mathrm{Na}$ atualidade, os projetos da IIRSA garantem o reforço dessas ligações leste-oeste - cujas obras chegaram até mesmo à Santiago e Lima -, e agora procuram caminhos para chegar ao norte chileno e sul peruano, seguramente mais atrativas aos polos industrias do Sudeste brasileiro.

É preciso lembrar que geopolíticos argentinos têm proposto e formação de lagos artificiais para a ampliação do calado dos navios que utilizam o Rio da Prata e seus afluentes mais importantes ${ }^{20}$. Entretanto, foi o governo brasileiro quem decidiu recentemente financiar a ampliação do porto de Montevidéu, estrategicamente localizado na foz do Rio da Prata, numa visível mudança de seus objetivos geopolíticos para a região, até então calcados na dissociação do povos hispano-americanos de sua geografia platina. Por certo, o Brasil deve assumir uma postura de hegemonia benevolente decorrente da projeção de seu poder regional, mas é impossível deixar de notar que o objetivo geopolítico brasileiro de desenhar a circulação regional apenas com ligações rodoferroviárias do interior do continente para o litoral brasileiro é ai abandonado. ${ }^{21}$

Na Bacia do Amazonas o desenho das articulações terrestres, especialmente da rodovia Manaus-Caracas poderá barrar a penetração de interesses estadunidenses no noroeste sulamericano, mas é preciso desenvolver o entorno da BR-174 para que não se transforme em mero "corredor de passagem" unindo o "nada a lugar nenhum".

Esperamos ter demonstrado ao longo deste texto que as premissas ratzelianas de controle territorial a partir da organização dos transportes fundamentada nos elementos da fisiografia e das bacias hidrográficas, continuam absolutamente válidas como norteadoras das tomadas de decisão política contemporâneas. Para finalizar, a eficiência da política nacional de circulação se deve em muito à abordagem geopolítica de Mário Travassos, seja

20. Martins (2011) cita BOSCOVICH, Nicolás, La Argentina en la Cuenca del Plata. In: PEDRAZA,Luis Dallanegra. Los países del Atlantico Sur.Buenos Aires: Editorial Pleamar, 1983

21. Para Travassos (1935, p. 74), a instabilidade geopolítica do Uruguai deriva de coexistir "Com o Brasil, laços sentimentais entretidos pela simplicidade de interesses pastoris e agrícolas. Com a Argentina, algo mais importante, interesses comerciais e militares de monta, criados e homogenizados pelo Prata e seu estuário". 
na soldadura da integração nacional ou na projeção continental dos interesses brasileiros, apesar dos deslizes recentes de nossa diplomacia.

\section{BIBLIOGRAFIA}

BANDEIRA, Moniz. A Guerra do Chaco. Revista Brasileira de Política Internacional. Brasília, n. 41, pp. 162-197, 1998.

ANTUNES, Antônio José Cerqueira. Infra-estrutura na América do Sul: situação atual, necessidades e complementaridades possíveis com o Brasil. CEPAL - Escritório do Brasil, Setembro de 2007.

GILPIN, Robert. O desafio do capitalismo global. Rio de Janeiro: Record, 2004.

GHIRARDELLO, N. À beira da linha: formações urbanas da Noroeste Paulista. [online]. São Paulo: Editora UNESP, 2002.

IIRSA. Disponível em http://www.iirsa.org/Page/PageDetail?id=119\&menultemld=68. Acesso em 12 de março de 2013.

MACKINDER, Halford J. O Pivô Geográfico da História. Revista de Geopolítica. Natal, v. 2, n. 2, 2011. Tradução de Thiago Alberto Coloda e Bianca de Andrade.

MARTINS, Marcos Antônio Fávaro. Mário Travassos e Carlos Badia Malagrida: dois modelos geopolíticos sobre a América do Sul. (Dissertação de Mestrado). PROLAM - Universidade de São Paulo, 2011.

RATZEL, Friedrich. Antropogeografia e Geografia Política. In MORAES, Antonio C. Robert. Ratzel. São Paulo: Ática, 1990.

SANTIAGO, João Phelipe. Espaço geográfico e Geografia do Estado em Friedrich Ratzel. Vitória da Conquista: Edições UESB, 2013.

TRAVASSOS, Mário. Projeção Continental do Brasil. São Paulo: Companhia Editoria Nacional, 1935. 2a. ed. ampl.

\begin{tabular}{r|r|}
$\begin{array}{r}\text { Artigo submetido em } \\
\text { Artigo aceito em }\end{array}$ 26/06/2014 \\
\hline
\end{tabular}

